\title{
Depression and Panic in Patients with Borderline Personality Disorder
}

\section{Leon Grunhaus, Douglas King, John F. Greden, and Pam Flegel}

\section{Introduction}

The borderline personality concept has evolved from a term used to describe a neuroticpsychotic borderland (Knight 1963), or an almost but-not-quite schizophrenic process (Hock and Polatin 1949), to a more precise and operationally defined syndrome (American Psychiatric Association, 1980; Gunderson 1982). Affective changes are a major and consistent clinical feature in most descriptions of borderline personality disorders (BPD). Major depressive disorder (MDD) or other DSM-III Axis I diagnoses, including panic disorder, may be present in a significant number of BPD patients, perhaps in the majority (Carroll et al. 1980; Akiskal 1981; Stone 1981; Pope et al. 1983). Thus, the appropriate treatment of patients with combined Axis I (MDD) and Axis II (BPD) pathology would require psychotropic medications. Pope et al. (1983) reported that BPD patients who had associated MDD and were treated with psychotropic medications had better outcome measures when interviewed 4-7 years after the index hospitalization.

Agoraphobia and panic disorder also have been reported as being occasionally associated

From the Department of Psychiatry, University of Michigan Psychiatric Hospitals, Ann Arbor, MI.

Supported in part by NIMH Grant MH019875 and by the Department of Psychiatry, University of Michigan.

Address reprint requests to Dr. Leon Grunhaus, Department of Psychiatry, University of Michigan Psychiatric Hospitals, 1405 East Ann Street, Ann Arbor, MI 48105.

Received November 20, 1984; revised December 4, 1984. with BPD (Akiskal 1981; Stone 1981; Pope et al. 1983); this is somewhat surprising, because early and current descriptions of BPD (Hock and Polatin 1949; Grinker et al. 1968; Kernberg 1975) repeatedly refer to pervasive anxiety and phobias as consistent features in BPD. One possible explanation for this relative low frequency of the reported association of BPD with anxiety disorders may be due to the design of the rating instruments and diagnostic systems used for the study of BPD. Current rating instruments, such as the Diagnostic Interview for Borderline (DIB) (Gunderson et al. 1981) or the Borderline Personality Inventory (BPI) (Perry and Klerman 1980), emphasize anxiety symptoms only vaguely. Those diagnostic systems with operational definitions of psychiatric entities, such as the DSM-III (American Psychiatric Association 1980) or the Research Diagnostic Criteria (RDC) (Spitzer et al. 1978), exclude anxiety diagnosis in the presence of significant dysphoria.

The diagnosis of panic disorder in patients with borderline disorder, either with or without MDD, may be of importance. BPD patients with associated panic may have a drug-responsive syndrome, thus increasing the possibilities of a favorable outcome (Akiskal 1981; Stone 1981). BPD patients with associated major depressive disorder and panic disorder may have distinctive clinical features, poorer treatment response, and increased chronicity of the illness (Leckman et al. 1983; Van Valkenburg et al. 1984). mitted). 
disorder in BPD patients, we analyzed the clinical features of 28 patients meeting the diagnosis of BPD, following Gunderson and Singer's (1975) criteria. Sixty-eight percent of the patients met both diagnoses of BPD and MDD, and $37 \%$ of these also had panic disorder. We found no patients with BPD and panic disorder in the absence of MDD.

\section{Methods}

The Clinical Studies Unit of the University of Michigan Hospitals is a research and treatment facility specializing in affective disorders. $\mathrm{Pa}$ tients routinely are evaluated with a diagnostic procedure consisting of: (1) a 14-day drug withdrawal period; (2) several independent clinical evaluations of psychiatric and medical complaints; (3) a structured diagnostic interviewSchedule for Affective Disorders and Schizophrenia; (4) a review of all past medical records to confirm longitudinal course whenever possible; and (5) a comprehensive physical examination and thorough laboratory screening to rule out serious medical illnesses. After completion of the baseline evaluation and research procedures, staff members meet in a weekly diagnostic conference to review data, integrate information, and compile diagnoses based on the Research Diagnostic Criteria (RDC) (Spitzer et al. 1978). Information on the patients included in this study was accumulated on an ongoing basis throughout the years 1976-1980.

\section{Subjects}

Patients had to meet the following inclusion criteria: (1) a diagnosis of borderline personality disorder following Gunderson and Singer's guidelines (Gunderson and Singer 1975), (2) a complete SADS interview with adequate ratings for panic attacks in the current episode of illness, and (3) the 17-item Hamilton Rating Scale for Depression (HRSD). The SADS interviews were analyzed for the presence of recurrent panic attacks. It is important to note that we diagnosed panic disorder even in the presence of MDD.
Twenty-eight patients met our inclusion criteria and were grouped according to diagnosis: Group $1(n=9)$, those with BPD alone; Group 2 $(n=12)$, those with BPD and MDD and no panic disorder; and Group $3(n=7)$, those with BPD, MDD, and panic disorder diagnosis. We then analyzed the HRSD ratings (total and items) and age distribution for the three groups of patients using a one-way analysis of variance. Categorical data were analyzed using a chi-square test.

\section{Results}

The sample consisted of 5 males and 23 females. The sex distribution was similar in the three groups of patients $\left(\chi^{2}=0.18\right.$, df $=2$, NS). The mean age was $28.57 \pm 8.6$ years; no significant age differences between the groups were identified ( $F=1.57$, NS). Of the 28 patients, $19(68 \%)$ met the diagnosis of MDD; of these, 7 (25\% of the total sample and $37 \%$ of the patients with MDD) had simultaneous MDD and panic disorder.

Table 1 presents the ANOVA results for the HRSD ratings. As mentioned previously, Group 1 represents those patients having just BPD, Group 2 those with MDD and BPD, and Group 3 those with BPD, MDD, and panic disorder. Significant differences between the groups occurred for the HRSD items of suicide $(p<0.05)$, somatic anxiety $(p<0.01)$, and hypochondriasis $(p<0.01)$; a significant trend was noted for the item of guilt. Although Group 2 had higher ratings for hypochondriasis, Group 3 rated highest for somatic anxiety, suicide, and guilt. When contrasts among the groups were made, the major significant differences occurred between those who have the three joint diagnoses and BPD alone (total HRSD, guilt, somatic anxiety, and suicidality).

\section{Discussion}

In this small sample of BPD patients, $68 \%$ had an Axis I diagnosis of MDD, and interestingly, $37 \%$ of these BPD and MDD patients also met our modified DSM-III criteria for panic disor- 
Table 1. Two-Way ANOVA of Significant HRSD Ratings (Total and Items) in Patients with BPD Alone (Group 1), MDD and BPD (Group 2), and MDD, BPD, and PD (Group 3)

\begin{tabular}{|c|c|c|c|}
\hline HRSD & Mean \pm SD & $F$ & Contrasts \\
\hline Total HRSD & $18.88 \pm 6.54$ & $1.922 \mathrm{NS}$ & \\
\hline Group 1 & $15.55 \pm 6.87$ & & (3 vs 2$) 0.09$ NS \\
\hline Group 2 & $20.18 \pm 6.75$ & & (3 vs 1$) 3.06^{a}$ \\
\hline Group 3 & $21.14 \pm 4.60$ & & $\begin{array}{l}(2 \text { vs } 1) 2.64 \mathrm{NS} \\
(3+2 \text { vs } 1) 3.80^{b}\end{array}$ \\
\hline Guilt & $1.25 \pm 0.94$ & $2.96^{a}$ & \\
\hline Group 1 & $0.77 \pm 0.83$ & & (3 vs 2 ) $1.88 \mathrm{Ns}$ \\
\hline Group 2 & $1.27 \pm 0.64$ & & (3 vs 1$) 5.92^{b}$ \\
\hline Group 3 & $1.85 \pm 1.21$ & & $\begin{array}{l}(2 \text { vs } 1) 1.56 \mathrm{Ns} \\
(3+2 \text { vs } 1) 3.90^{b}\end{array}$ \\
\hline Suicide & $1.79 \pm 1.09$ & $3.62^{b}$ & \\
\hline Group 1 & $1.33 \pm 1.00$ & & (3 vs 2$) 4.35^{a}$ \\
\hline Group 2 & $1.63 \pm 1.12$ & & (3 vs 1 ) $6.77^{c}$ \\
\hline Group 3 & $2.64 \pm 0.74$ & & $\begin{array}{l}(2 \text { vs } 1) 0.45 \mathrm{NS} \\
(3+2 \text { vs } 1) 2.56 \mathrm{NS}\end{array}$ \\
\hline Work and interests & $2.29 \pm 1.04$ & $1.94 \mathrm{NS}$ & \\
\hline Group 1 & $1.77 \pm 1.30$ & & (3 vs 2$) 0.28 \mathrm{Ns}$ \\
\hline Group 2 & $2.45 \pm 0.68$ & & (3 vs 1$) 3.42^{a}$ \\
\hline Group 3 & $2.71 \pm 0.99$ & & $\begin{array}{l}(2 \text { vs } 1) 2.24 \mathrm{NS} \\
(3+2 \text { vs } 1) 3.42^{a}\end{array}$ \\
\hline Somatic anxiety & $1.12 \pm 0.95$ & $5.46^{c}$ & \\
\hline Group 1 & $0.55 \pm 0.528$ & & (3 vs 2$) 4.40^{b}$ \\
\hline Group 2 & $1.09 \pm 0.949$ & & (3 vs 1$) 10.90^{\circ}$ \\
\hline Group 3 & $1.92 \pm 0.930$ & & $\begin{array}{l}(2 \text { vs } 1) 2.08 \mathrm{NS} \\
(3+2 \text { vs } 1) 5.70^{b}\end{array}$ \\
\hline Hypochondriasis & $0.48 \pm 0.75$ & $7.65^{c}$ & \\
\hline Group 1 & 0 & & (3 vs 2 ) $2.23 \mathrm{NS}$ \\
\hline Group 2 & $0.90 \pm 0.94$ & & (3 vs 1$) 1.63 \mathrm{NS}$ \\
\hline Group 3 & $0.42 \pm 0.53$ & & $\begin{array}{l}(2 \text { vs } 1) 9.24^{b} \\
(3+2 \text { vs } 1) 6.70^{c}\end{array}$ \\
\hline
\end{tabular}

$$
\begin{aligned}
& { }^{a} p<0.1 . \\
& { }^{b} p<0.05 . \\
& { }^{c} p<0.01 .
\end{aligned}
$$

der, thus having two associated Axis I diagnoses. None of the patients had panic disorder in the absence of MDD. The patients with BPD, $M D D$, and panic had higher HRSD ratings than patients with BPD alone. This in itself is not surprising, because the HRSD is assessing affective changes in this population. However, particular items of the HRSD scale were significantly different between the groups, whereas the depressed mood rating was not. Overall patients with BPD, MDD, and panic seemed more guilty, suicidal, and somatically anxious. These findings are applicable to a population of hospitalized BPD patients. It is unclear whether or not they can be generalized to all BPD patients. The heuristic value of this report lies in the identification of a subgroup of BPD patients that may be pharmacologically treatable.

Recent reports suggest that patients who have joint MDD and panic disorder might differ from those with pure MDD on several parameters. First, with regard to clinical features (Grunhaus et al. 1984; Van Valkenburg et al. 1984), it has been noted that patients with joint MDD and 
panic have lower ratings for guilt and depression and higher ratings for hypochondriacal features, somatic and psychological anxiety, and depersonalization and derealization. Second, the treatment response, the psychosocial outcome, and the chronicity of the illness (Van Valkenburg et al. 1984) seem to be worse in patients with both conditions. Third, Leckman et al. (1983) have shown that patients with joint MDD and panic have a higher incidence of family pathology, whether anxiety, depression, or alcoholism, than patients with MDD or panic alone. Fourth, the biological features (Grunhaus et al. 1984) are affected in that the sensitivity and specificity of the Dexamethasone Suppression Test seems to be lower in patients with MDD and panic than in a matched group of patients with MDD alone; also, the REM latency of patients with the joint syndrome approaches normal values and does not show the reported low REM latency of MDD patients.

Pope et al. (1983) stressed the importance of adequate drug treatment of those BPD patients with MDD. He found that BPD patients with MDD who were pharmacologically treated had a tendency for better long-term outcome and global assessments and more successful occupational status. Also, 6 of 14 patients with BPD and MDD at baseline had no identifiable borderline features during the follow-up interviews, which occurred 4-7 years after the index hospitalization, suggesting that the initial personality pathology was secondary to the affective process. The authors did not report whether or not MDD was associated with panic disorder. The rating instrument (the DIB) and diagnostic classification (the DSM-III) used by these authors did not allow this distinction. However, two of their patients met BPD and panic diagnoses.

The presence of affective and panic pathology in BPD patients seems to confer some particular characteristics on the clinical picture. This may also be true with regard to the treatment response. The finding (Pope et al. 1983) that some patients may not reveal BPD pathology after successful treatment for their MDD is very intriguing and may mean that some of the more classical borderline features, such as acting-out behavior, severe mood swings, drug abuse, etc., are in fact state, and not trait, related. The need for a pharmacological trial of antidepressants, particularly monoamine oxidase inhibitors, in these patients is stressed by the favorable outcome described for patients with atypical depression and panic attacks when treated with phenelzine (Liebowitz et al. 1984). Both affective and panic pathology may be responsible for these mood-related features of borderline patients and should be addressed when performing diagnostic assessments or treatment recommendations for these patients.

\section{References}

Akiskal HS (1981): Subaffective disorders: Dysthymic, cyclothymic and bipolar II disorders in the "borderline" realm. Psychiatr Clin North Am 4:25-46.

APA (1980): Diagnostic and Statistical Manual III. Washington, DC: American Psychiatric Association.

Carroll BJ, Greden JF, Feinberg M (1980): Evaluation of depression in borderline patients. American Psychiatric Association, annual meeting, San Francisco.

Grinker RR, Werble B, Drye RC (1968): The Borderline Syndrome. New York: Basic Books.

Grunhaus L, Rabin D, Greden JF, Hermann R, Feinberg $M$ (1984): Simultaneous panic and depressive disorder: Neuroendocrine and sleep EEG correlates. Society of Biological Psychiatry Annual Meeting. Los Angeles.

Gunderson JG (1982): Empirical studies of the borderline diagnosis. In Grinspoon L (ed), Psychiatry 1982 Annual Review. American Psychiatric Press.

Gunderson JG, Singer MT (1975): Defining borderline patients: An overview. Am J Psychiatry 132:1-10.

Gunderson JG, Kolb JE, Austin V (1981): The Diagnostic Interview for Borderlines (DIB). Am J Psychiatry 138:896-903.

Hamilton M (1960): A rating scale for depression. J Neurol Neurosurg Psychiatry 23:56-62.

Hock P, Polatin P (1949): Pseudoneurotic forms of schizophrenia. Psychiatr Q 23:248-276.

Kernberg O (1975): Borderline Conditions and Pathological Narcissism. New York: Jason Aronson.

Knight RP (1953): Borderline states. Bull Menninger Clin 17:1-12.

Leckman JF, Weissman MM, Merikangas KR, Pauls DL, Prusoff BA (1983): Panic disorder and major depression. Arch Gen Psychiatry 40:1055-1060. 
Liebowitz MR, Quitkin FM, Stewart JW, McGrath PJ, Harrison W, Rabkin J, Tricamo E, Markowitz JS, Klein DF (1984): Phenelzine vs. imipramine in atypical depression. Arch Gen Psychiatry 41:669-677.

Perry JCH, Klerman GL (1980): Clinical features of the borderline personality disorder. Am $J$ Psychiatry 137:167-173.

Pope HG, Jonas JM, Hudson JI, Cohen BM, Gunderson JG (1983): The validity of DSM-III borderline personality disorder. Arch Gen Psychiatry 40:23-30.
Spitzer RL, Endicott J (1975): Schedule for Affective Disorders and Schizophrenia. New York: Biometrics Research Division, New York State Psychiatric Institute.

Spitzer RL, Endicott J, Robins E (1978): Research Diagnostic Criteria. New York: Biometrics Research.

Stone MH (1981): Borderline conditions: Or consideration of subtypes and an overview. Directions for research. Psychiatr Clin North Am 4:3-24.

Van Valkenburg CH, Akiskal HS, Puzantian V, Rosenthal T (1984): Anxiety depressions. J Affective Disord 6:67-82.

\title{
Resting Metabolic Rate is Reduced in Patients Treated with Antidepressants
}

\author{
Madelyn H. Fernstrom, Leonard H. Epstein, Duane G. Spiker, and \\ David J. Kupfer
}

\section{Introduction}

Eating disturbances, most notably a decrease in appetite and weight loss, are associated with major depression (Robinson et al. 1975; Paykel 1977; Mezzich and Raab 1980). During antidepressant treatment, many symptoms of depression disappear (including appetite loss), and patients begin to gain weight. Several studies have shown that certain antidepressants, particularly tricyclic compounds, are associated with excessive weight gain (Paykel et al 1974; Kupfer et al. 1979; Berken et al. 1984). However, few

From the Department of Psychiatry and Center for Neuroscience, University of Pittsburgh School of Medicine, Pittsburgh, PA Supported in part by Mental Health Clinical Research Center Grant MH 30915.

Address reprint requests to Dr. M. H. Fernstrom, Western Psychiatric Institute and Clinic, 3811 O'Hara Street, Room E-1228, Pittsburgh, PA 15213.

Received November 17, 1984; revised December 26, 1984. comprehensive data exist that focus on factors influencing weight change upon recovery from a depressive episode.

Weight fluctuations reflect both caloric intake and caloric expenditure. Thus, weight gain is due to positive energy balance, which may be explained by an increase in total calories consumed and/or a reduction in calories used by the body. Resting metabolic rate (RMR), which reflects the number of calories utilized by an individual in a resting state, represents at least $70 \%$ of the total caloric utilization by an individual (Garrow 1978); RMR probably accounts for an even greater proportion of calories in hospitalized patients due to their greater inactivity. Therefore, if a reduction in metabolic rate occurs, an individual would gain weight without increasing caloric intake. Thus, we wanted to determine whether or not alterations in resting metabolic rate might occur in drug-treated depressed patients; such changes might ultimately contribute to potential weight changes. 